Session 3630

\title{
IMPROVING TEACHING QUALITY THROUGH TOTAL QUALITY MANAGEMENT
}

\author{
Richard Lundstrom, Jawaharlal Mariappan and K. Joel Berry \\ GMI Engineering \& Management Institute
}

\begin{abstract}
This paper presents the experience gained and the lessons learned while implementing a Total Quality Management (TQM) approach in teaching two courses at GMI Engineering \& Management Institute. The primary purpose of this effort is to improve the quality of engineering design education. The many other benefits of this approach include increased student involvement, a systematic way to evaluate students, discernment and objective measures for teacher performance and the development of an environment of trust, faculty teaching portfolio and emphasizing the teacher as a quality manager in the classroom. This paper describes in detail several issues involved in the development of a TQM approach in classrooms. Specifically, it elaborates on the ground work needed to implement such an approach, development of a common shared vision for the course, the delivery methods to effectively carry out instructions and exercises to enhance student involvement. The courses included are mechanism design and automotive chassis design. They are required courses in Mechanical Engineering at GMI for the machine design and automotive specialties respectively.
\end{abstract}

\section{Introduction}

There has been increased attention on improving the quality of engineering education in the country. Engineering educators (Bieniawski, 1995; Cage, 1995; Dixon, 1991; Furman, 1995; Howel et al, 1995; Wilczynski and Douglas, 1995) have been addressing several issues such as integrating design education into the engineering curriculum to improve the quality of engineering graduates. The Accreditation Board for Engineering and Technology (ABET) has adopted new guidelines for the recognition of engineering programs. ABET requirement of minimum number of design credits from any combination of courses has been changed, and now it is necessary for the engineering schools toprovide an integrated design experience that builds upon the fundamentals of basic, engineering anti socia I sciences. Furthermore this experience must be developed in a systematic way and integrated throughout the curriculum. This new approach and expectations are radically different and require engineering educators find new ways to teach the material and stay current with quality management such as TQM in addition to staying ahead of this trend.

The current structure of engineering education has been shaped by the principles and guidelines developed years ago. The primary focus on research at academic institutions, attempts to bring professor's research contributions into the undergraduate curriculum at the expense of fundamental engineering courses 
and absence of new courses that incorporate the latest in technology are some of the. few factors that add to the complexity of undergraduate engineering education. As business in the US and other parts of the world adopt reengineering and total quality development approaches to change the way they have been functioning for decades, academia too needs to take suitable measures to meet the new challenges. Improving the quality of education by adopting TQM principles is one step towards a radical change in engineering education.

American universities have been facing the pressure that have been faced by their business counterparts over the last decade: increasing costs, intense international competition and demanding customers. Universities have become aware that they are not so much different from businesses. Schools such as MIT, University of Chicago are reengineering their administrative processes to control costs and to focus on their customers. One very important Customer is the student. While reorganization of administrative aspects of universities is becoming a reality, surprisingly not much has been done to bring corresponding changes in the class rooms. The works by Langford (1994), Glasser $(1986,1993)$ and Cornesky $(1993,1994)$ deal with TQM principles in education. Their works provide tips and quality classroom practices to instructors. This paper deals with the implementation of some aspects of the Total Quality Management Approach in teaching at GMI. Two courses, namely, Chassis Design and Design of Mechanisms that have been taught by the authors were selected for this study. These are traditiona I courses offered junior/senior level students and heavily design oriented.

\section{Our Paradigm}

Our attempt to incorporate TQM principles is based on the premise developed by Glasser. William Glasser, M. D., a world renowned practicing psychiatrist, has been teaching and researching in the areas of control theory of human behavior and reality therapy. He has lead the development of the quality school program and has made significant contributions to the psychology pillar of profound knowledge. According to Glasser, quality is anything we experience that is consistently satisfying to one or more of a person's five basic needs. This definition is based on the control theory of human behavior. This theory holds that all human beings have five basic needs: love, power, freedom, fun and survival. These are built into our genetic structure, and from birth we must devote our behavior attempting to satisfy them.

With this definition of quality it is possible to understand why quality is personal. Each person's mental "picture" of what is required to satisfy their basic needs is different! This is the case for our learning colleagues, the students. Learning requires the aim, method and the teachers immersed in delivering the learning environment be accepted into the learner's quality world. This is very difficult but necessary to facilitate if we want quality learning to occur. Teaching professors therefore need to acquire the knowledge, wisdom and skills necessary to be quality managers (or leaders) in our classrooms and laboratories.

\section{Students As Colleagues}

The current educational structure is so formal that usually, there is no room for anything other than lecturing. In such an atmosphere, the students act only as passive listeners. This has been the predominant method of teaching for decades. One approach to get students involved in the educational process, not $\mathrm{j}$ ust as passive listeners but as active participants who play a major role in defining the course objectives and ground rules, is to accept them as colleagues in learning. Like any another new method this is also very difficult to implement unless one really feels it's right and is committed to it. Usually this type of approach requires a paradigm shift (Covey, $1989 \&$ 1990). The effect of a paradigm shift of treating the students as 
colleagues can be dramatic. By accepting and treating students as colleagues, one not only changes the traditional educational course established decades ago but also adds a new meaning to the student-professor relationship. First of all, students are not merely viewed as customers in a "department store" but as equal partners who play a role in creating the learning process. It is important to add that the teacher must also serve as leader and facilitator for this learning process, the teacher is the source of wisdom and needs to help the students develop their own wisdom.

We have been largely successful in adopting this approach in our courses. The success is based upon recognizing that this is a necessary component of a learning environment and that we really mean this and treat students as colleagues. This has helped us to work with students to develop the course purpose. This allows the source of wisdom relative to the course material, the teacher, to communicate through the student, the course purpose. This also allows the student to "buy into" the course and be better prepared to immerse themselves in the experience.

\section{Building Trust}

In order for the students to truly accept and work with an instructor, they must first trust the instructor. While everyone agrees that an environment of trust is the single most important factor for active learning, it is not clear or well established on how such an atmosphere can be developedin the context of engineering education. The authors have found that treating the students as colleagues is one effective way to develop a true learning environment.

According to a recent study (ASEE Prism, 1995), today's students give more weight to an instructor's interpersonal skills and enthusiasm than to his or her knowledge of the subject matter. This is not to suggest that students do not consider subject knowledge important. In fact, subject knowledge is a close second. This is really not a surprise because students especially at an undergraduate level learn more if the instructor can motivate and inspire the students than a research-oriented professor who may have vast knowledge of subject matter but may not be able to connect well with the students. Instructor's commitment and competency are the key factors in establishing an environment of trust.

One possible way to gain student trust is to ask them to set the ground rules for the course. In the early sessions, we usually ask the students to set the grading policy, schedule for turning in homework assignments, projects, exams and groundrules for the course. Students are also asked to discuss and suggest the weight of each of the category in the final grade. This whole procedure should be done carefully without imposing one's own personal bias. Instructors role during this time is more like facilitator rather than a lecturer. It must be noted that it is a difficult to gain students' trust. It is a slow but highly rewarding process. This process gives the students a chance to voice their opinion, understand the course requirements and the difficulty in finding a solution acceptable to everyone. In the process students come to realize they are learning colleagues with the instructor.

\section{Connecting to the Students}

In addition, to get the student involvement in the course, it is necessary to look for possibilities to directly relate them to the course being taught. For example, in chassis design course each student is asked about their favorite vehicle. When the students identify their favorite vehicle, a direct connection is made to the course, and a discussion follows. A similar approach is used in the mechanisms' class. GMI's unique cooperative academic program is very helpful in making the connection between the students and courses. 
This program allows the students alternatively to study for three months and work three months at a corporate partner's site. Faculty members who teach other courses will find it helpful to develop specific plans for each course to accomplish this connection.

Once a connection between students interests and the course is established, students will show a natural enthusiasm for the course. This is extremely important because students, in general, take courses because they are required to take it. The current structure allows the perception that engineering is a collection of courses that need to be taken in some sequence. This perception misses the underlying philosophy and the thread integrating all engineering disciplines.

Students must be involved, as learning colleagues in the process of defining the objectives for the course, and also how these objectives will be met. The instructor can state what are the terminal competencies that must be achieved for the course. The students must be made aware of the value of these competencies and their interrelation to other disciplines. With this step, the instructor can broadly state his or her mission for the course. It is equally important for the instructor to specify how he or she would achieve this mission. By doing this, the instructor demonstrates the leadership and commitment to the class. Students usually respond well to this attitude. They see that the instructor is concerned, and really cares for them.

With students involvement in developing course objectives and ground rules, it is time for a personal mission statement from each student. In mechanisms' course, one of the assignments included an optional question asking the students to come up with a mission statement for the course, and their commitment to achieve this mission. This happens at a time when certain amount of confidence has been established between the faculty and the students, and the students have had a chance to listen to the instructor's mission statement. In our classes, we had all of our colleagues in learning providing their own mission statement for the course.

\section{Self Evaluation Concept from William Glasser to Improve Teaching}

We are attempting to apply William Glassar's $(1986,1993)$ recommended process for self evaluation with the aim of producing quality work, in our case, quality teaching in the classroom and laboratory. A deliberate process is important when improved quality, reduced cost, and reduced delivery time (QCD) are important. We think this is the situation in teaching. There is a high interest in improved quality, in fact this has always been true in higher education. There is always a limit on cost, certainly the institutions of higher learning which are able to minimize tuition inflation will have an advantage if this is consistent with continually improved quality and delivery time. Delivery time is also critical since the student as well as current and potential employers would like a degree in a reasonable time, or even in a minimum time. As teachers we insist on our students achieving defined competencies before a degree is granted and the students and employers also require this, certainly when they are given professional responsibility. So in learning and in facilitating student colleagues to do quality work we need deliberate processes to help us. We have found William Glasser's SESIR process for developing quality work to be very helpful in our struggle to continually improve as teachers. The process is briefly described here:

SHOW someone who is interested, a student colleague or faculty colleague, what we are doing. Do it carefully and completely so that this person can easily see that this is what we did,

If it is not obvious, to the person, or if there are questions, EXPLAIN to that person how we achieved what we are showing them. 
After we do this, we evaluate (ELF-EVALUATE) what we did to see if it could be improved. Most of the time it is obvious that we could IMPROVE what we are doing, so we continue working to try to improve it.

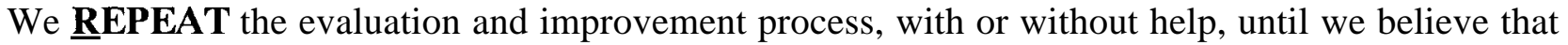
further attempts at improvement are not worth the effort. At this time, we believe we have done what deserves to be called quality.

We are attempting the use of self evaluation to produce quality in our teaching so that this will allow us to become models for our student colleagues and present them with examples of a process which can facilitate producing quality work. In our work this will directly benefit the student, even though they may not notice immediately. Some examples of concepts we are using to facilitate SESIR are reinforcement, competency portfolios, readiness reports, on the spot reviews of assumed competencies, vehicle of choice survey and student colleague summaries.

\section{Competency Portfolio}

In the chassis design course the student colleagues are asked to develop a competency portfolio. The instructor's check list for this is shown in Figure 1. The check list format also includes an evaluation strategy and content requirements. The students are provided this early in the course, usually in the second week. this gives the teacher time to begin establishing an atmosphere of trust and learning in the classroom and laboratory. This document contains only the students best work in each area. The idea of reinforcement is used to assist the teacher in facilitating the student to develop better and better work and to submit only their best. Our aim is to have this display of work include examples of quality work and were this level of achievement has not been reached we encourage them to display and describe their progress toward this goal and a plan of attach to eventually achieve competency, even after they complete the course. We hope this contributes also to the student colleague's interest in life long learning. They are encouraged to add areas as they develop them. This usually occurs as they are working with their vehicle of choice.

\section{Readiness Report}

One common complaint that engineering educators have is that students lack necessary background or prerequisite knowledge. This is really a systems problem, roots of which to lead to high school education. However, instead of blaming the system, quality professors must face this issue head-on and address it. Working in an environment of trust with student colleagues, we outline the techniques that students need to clearly understand before we start using them. For example, it is expected students have a good knowledge of linear algebra in the mechanisms' course. However, in reality, many students do not have the necessary background. Since, GMI students alternate twelve weeks of work and twelve weeks of academic study, many students tend to easily forget the material previously covered. If we simply leave it for the students to figure out, and most of them usually do not follow the material and give up. To avoid this situation, we have prepared a readiness report that highlights the areas necessary to know with brief background information. This report also includes some examples showing the relevance of this material for the course. In addition, we have organized extra help sessions for those who decide they need it. However, our objective is to completely avoid these extra help sessions that teach material that the student are supposed to know. We view these session as a type of repair work. If quality job has been done in the first place, probably there would not have been any need to do repair work. Since we do not live in an ideal environment, we do conduct these sessions periodically. 


\section{Vehicle of Choice Survey}

The colleagues in chassis design are asked to pick a vehicle of their choice. This could be their dream vehicle, a vehicle they own or vehicle they are involved with at their work site. They just simply like the vehicle for some reason. The professor facilitates this and also participates by selecting a vehicle choice, this permits an example for the students to reference. The survey is conducted on the first day of class and is verbal. At random, colleagues choices are used as examples to facilitate defining chassis design and its elements as well as the areas which the course has been developed to emphasize. One choice may be used to discuss suspensions and another may be used to discuss tires, etc. This survey generally takes the entire first class period, depending on the size of the class (the largest class to date has been 61 colleagues). However, at the end of the survey the following important items have been covered:

- Each colleague has introduced themselves and were they are employed,

- the course content has been introduced,

- the spectrum of vehicles to be considered has been established,

- automotive chassis architecture and chassis design have been defined,

- the general aim and mission of the course has been established,

- the professor has been given an idea of the spectrum of interest and knowledge level of the student colleagues.

This list of course contains nothing new, however, in this case the student colleagues have participated in the development and assisted in establishing a list of practical chassis architecture examples which can be used during the course and this helps to immerse them in the course experience. In addition to this each student is asked to develop their competency in defining vehicle architecture by composing a presentation, using their vehicle of choice. This presentation is part of their competency portfolio to be given to the professor at the end of the course. The instructor is available at anytime to review the student colleague's portfolio work and make comments and suggestions for improvement. This last element of the survey introduces the student colleagues to the competency portfolio building process. Any professor in any course could use this concept to connect with the student colleagues and help to immerse them in a learning experience relative to the course material.

\section{Student Summaries}

As a regular practice, in our classes, each student is requested to briefly (about 3 minutes) recap the material covered in the previous class. Although some students are reluctant initial I y, this practice made the students go through the material before coming to the class. Similarly, at the end of each class, a student summarizes the days work. This practice usually makes them more attentive in the class, and stimulates questions when they do not understand. This involvement is considered as class participation.

\section{Quality Tools -- Check Lists}

The check list is a common tool and probably has been used for centuries. History records its use by Benjamin Franklin (Roberts, 1993). In chassis design they are used for communicating the requirements of assignments and the check list is combined with document content requirements and the evaluation of work, Examples of this format are shown in Figures 1 and 2. This also presents the student with an operating check list they can use to help manage their progress on the assignment. The document content portion can also be seen in the figures. The evaluation portion is represented by the performance scale; E for excellent, $G$ for 
good, $\mathrm{F}$ for fair, $\mathrm{P}$ for poor and $\mathrm{U}$ for unacceptable. This evaluation strategy is correlated to our numerical grading system at GMI. We have found that check lists can be continually modified for improvement and provide at a glance a view of the current best outline for the course, experience or experiment requirements.

\section{Course Handbook}

A handbook has been developed for the chassis design course (as well as courses such as mechanical control systems). This document is continually improved based primarily on improvements suggested by student colleagues and improvements made in the course. It contains summaries of important topics and user friendly summaries of the simulators used for making predictions of vehicle performance in areas relative to course topics. The intention is to serve as an example of a professional reference which can be used on the job for adding value to the successful pursuit of an assignment. An example is shown for chassis design in Figure 3. It can be seen that it also incorporates the check list, handbook content and evaluation. In this case the evaluation is solicited from the students and improvements are made based on their suggestions.

\section{Faculty Team}

Teams are an essential ingredient in the struggle to perform at a quality level. We believe this is true for any area of pursuit, including teaching. The authors decided to form a teaching team focusing on deliberate improvement of our teaching. This of course includes continual improvement of our ability to be quality managers in the classroom and the ability to create a learning environment in our classrooms and laboratories. This team was established voluntarily based on our mutual interest in exploiting the power of quality to improve our teaching. To be effective teams need a vision, a mission and values. Presented here is the current state of this team's effort to establish guidance for our work.

Our vision is to create a learning environment in the classroom and laboratory and help our learning colleagues to achieve their own understanding of the course purpose and material, and to do quality work.

Our mission is learning, to learn and help others to learn and preparing people to add value to themselves and to society through the profession of engineering.

Our values include:

- Using a holistic approach to quality which includes profound knowledge and Dr. Deming's (1993) fourteen points,

- Using a holistic approach to deliberate improvement,

-We will treat people with dignity and respect,

-We will treat students as colleagues in learning,

-We pursue the seven habits of highly effective people.

We also require our learning colleagues to form teams and develop team experiences with them. These team experiences enhance learning and some of our experiences are summarized in the discussion on team learning experiences.

\section{Reinforcement}

Reinforcement can be used when fundamental course material is presented. Initially the fundamental concept is presented and quite often this includes the development of a simulation. In chassis design this might be lateral weight transfer. Then an example is presented using a vehicle of choice, including a data 
base so predictions can be made through the use of the simulation and calculations. A quiz is then given in class(about twenty minutes), again using a vehicle of choice, usually different than the lecture or lab example, each student is required to submit a solution. However, the quiz is reviewed by the professor using visual-aids, before students begin. The student colleagues are asked to make any questions or comments during the twenty minute period aloud so the entire class has access to the information and the teacher's comments. A complete solution is provided each person as they submit their work. the work is graded and then returned. Then the same fundamentals are incorporated in a team experience (a check I ist for one of these experiences is shown in Fig. 2). These experiences include physical experiments on a case study vehicle and engineering design experiences. This permits the students to learn from each other and then develop a presentation in the form of a team document. It can be seen by revisiting Fig. 2 that the document content requirements as well as an evaluation strategy are again part of the check list. The student has access to this three level reinforcement and can use this to help them to develop a presentation of their individual competency, including their own examples, in the competency portfolio. This reinforcement process involves four major steps and thus provides four levels of reinforcement. The aim here is of course to help the student colleague to develop their own competency and facilitate their application of deliberate improvement exploiting the teacher as a facilitator.

\section{Hands-On Teaching Techniques}

There is unanimous agreement on providing the students with hands-on experience in design courses. However, often this simple statement is difficult to implement due to the lack of projects or facilities or for other reasons. As a part of our TQM approach, we decided to provide the students with an automobile in the mechanism course for hands-on exercises. GM Powertrain donated a new Buick LeSabre for educational purposes. Student colleagues were asked to identify mechanisms in the car, take apart certain mechanisms, reassemble them on a bench, conduct physical experiments, generate a computer model, perform analysis and simulation, suggest design improvements, and produce a report and professional presentation. Thus the students had a chance to acquire skills necessary to identify and disassemble individual mechanisms from a complete system. This exercise further reinforced the connection of this course to complete systems. It is a unique project pioneered at GMI.

\section{House of Quality (HQ)}

In our design projects, we expect the student colleagues to develop a HQ (Clausing, 1993; Hauser \& Clausing 1988) that clearly illustrates the customer needs, related engineering characteristics, the targets, design parameters and their interrelationship. Since students had not been previously exposed to these quality tools, we had to dedicate a 30 minute session on HQ. We also provided the students with more information on HQ and successful case studies from the industry. Introducing HQ to the classroom has been very useful. All the students developed a HQ in some form. This required that student teams visit many sites. For example, a team involved in the design of the power steering linkage system for a tractor made several visits to the local John Deere Tractor dealer. Another team involved in the design of a window regulator for a car established contacts with the original designers.

\section{Team Learning Experiences}

Much of the work in the class can be best done as groups. We use several team building exercises in our class rooms to bring the members together. In the mechanisms course, individual assignments were made different for two home work assignments. There were 21 students in the class and 21 separate 
assignments were made. These assignments related to the same topic, had the same level of complexity but were unique. In the mechanisms course, 30 synthesis problems were provided and the students were asked to choose any one. Students were allowed, actually encouraged to work together on this assignment.

Although the burden on the faculty is high to create and grade assignments like this, the results are amazing. Students worked together trying to solve each problem. We had students who were involved in solving as many as 12 problems. Assigning the same problem to everyone would not expose these students to so many different real world problems. Students were so excited that they met among themselves outside classrooms and discussed these problems and the proposed solutions.

\section{Summary and Future Plans}

The authors are committed to the struggle for deliberate improvement and the pursuit of quality teaching and learning. This requires a deliberate effort and perseverance but we are convinced that our teaching and learning are improving and we are becoming better professionals in the process. We will be continuing the effort we have described in this paper and are considering these additions:

Use improvement surveys continually during courses. This has been experimented within another course and has been useful. This survey asks the following questions:

What have you learned?

What has worked?

What has been confusing?

What needs to be changed?

This allows the student colleagues to give the teacher constructive independent input which can be used to improve the class immediately. It also allows the teachers to see how effective they are, and the students can see their ideas have value. This method can also be used to develop the student's skill in formulating suggestions for improvements that have a chance of being accepted and implemented.

Use of Dr. Clausing's total quality development process for course development. This process includes, basic concurrent engineering, enhanced quality function deployment and quality engineering using robust design.

Use the theory of five whys (Shigeo, 1989 \& Ohno, 1988) to improve teaching and learning.

Make use of multi-media notebook computer based presentations in our classes. This will allow us to respond faster to suggestions for improvements and make modifications immediately so they can be developed interactively with our student colleagues. 
GM I

\section{Engineering \& Management Institute ME-421 \\ CHASSIS DESIGN}

Competency Check List and Evaluation Sheet
Ott-Dee, 1995

Richard R. Lundstrom, Ph.D.

Office: 1-733AB

Hours: 0900 to 0950, MTuW

also by appointment

TEL

FAX

email: rlundstr@beretta.gmi.edu

PURPOSE:

\section{UNDERSTANDING AUTOMOTIVE CHASSIS DEVELOPMENT AND HOW IT IS RELATED TO PROVIDING QUALITY RIDE AND HANDLING PERFORMANCE}

\begin{tabular}{|c|c|c|c|c|c|c|}
\hline Performance Scale & $\sqrt{ }$ & $\mathrm{E}$ & $G$ & $\mathrm{~F}$ & $\mathrm{P}$ & $U$ \\
\hline : & & & & & & \\
\hline Chassis Architecture & & & & & & \\
\hline Chassis Architecture Fundamentals & & & & & & \\
\hline S & & & & & & \\
\hline Steering & & & & & & \\
\hline Tires and Wheels & & & & & & \\
\hline Brakes & & & & & & \\
\hline Frame/Body & & & & & & \\
\hline Weight Distribution & & & & & & \\
\hline Weight Distribution Fundamentals & & & & & & \\
\hline Vehicle Weight Distribution & & & & & & \\
\hline Sprung Weight Distribution & & & & & & \\
\hline Unsprung Weight Distrbution & & & & & & \\
\hline Vehicle Moment of Inertia & & & & & & \\
\hline Unsprung Weight Pitch Moment of Inertia & & & & & & \\
\hline Vehicle Roll Moment of Inertia & & & & & & \\
\hline Unsprung Weight Roll Moment of Inertia & & & & & & \\
\hline Vehicle Yaw Moment of Inertia & & & & & & \\
\hline & & & & & & \\
\hline Ride Management & & & & & & \\
\hline Ride Management Fundamentals & & & & & & \\
\hline -Damping & & & & & & \\
\hline - Ride Frequency Attributes & & & & & & \\
\hline - Quarter Vehicle Simulator & & & & & & \\
\hline - Pitch Plane Model & & & & & & \\
\hline Wheel Rates & & & & & & \\
\hline Ride Rates & & & & & & \\
\hline Tire Rates & & & & & & \\
\hline Sprung Weight and Unsprung Weight Natural Frequencies & & & & & & \\
\hline $\begin{array}{l}\text { Sprung Weight Pitch and Bounce Natural Frequencies and Node } \\
\text { Locations }\end{array}$ & & & & & & \\
\hline Figure & & & & & & \\
\hline
\end{tabular}




\begin{tabular}{|c|c|c|c|c|c|c|}
\hline Performance & $\sqrt{ }$ & $\bar{E}$ & $\mathbf{G}$ & $\mathrm{F}$ & $P$ & $\mathrm{U}$ \\
\hline \multirow{2}{*}{\multicolumn{7}{|c|}{ Pitch Management }} \\
\hline & & & & & & \\
\hline \multicolumn{7}{|c|}{ Pitch Management Fundamentals } \\
\hline \multicolumn{7}{|c|}{ - Pitch Management Attributes } \\
\hline \multicolumn{7}{|c|}{ - Chassis Acceleration Forces } \\
\hline \multicolumn{7}{|c|}{ - Chassis Braking forces } \\
\hline \multicolumn{7}{|l|}{ Anti-Dive } \\
\hline \multicolumn{7}{|c|}{ Anti-Lift } \\
\hline \multicolumn{7}{|c|}{ Suspension Geometry Requirements } \\
\hline \multirow{2}{*}{\multicolumn{7}{|c|}{ Steering Wheel Angle Management }} \\
\hline & & & & & & \\
\hline \multicolumn{5}{|c|}{ - Tire characteristics } & & \\
\hline \multicolumn{7}{|c|}{ - Steering Geometry Requirements } \\
\hline \multicolumn{7}{|l|}{ - Bicycle Model } \\
\hline \multicolumn{7}{|c|}{ - Steering Wheel Angle Management Attributes } \\
\hline \multirow{2}{*}{\multicolumn{7}{|c|}{$\begin{array}{l}\text { Ackerman Steering } \\
\text { Understeer Gradient }\end{array}$}} \\
\hline & & & & & & \\
\hline \multicolumn{7}{|c|}{ Sprung Weight Roll Management } \\
\hline \multicolumn{7}{|c|}{ Sprung Weight Roll Management Fundamentals } \\
\hline \multicolumn{7}{|c|}{ - Roll Management Attributes } \\
\hline \multicolumn{7}{|c|}{ - Steering Wheel Angle Management } \\
\hline \multicolumn{7}{|c|}{ - Understeer Gradient } \\
\hline \multicolumn{7}{|c|}{ Steering Geometry Requirements } \\
\hline \multicolumn{7}{|c|}{ Wheel Geometry Requirements } \\
\hline \multirow{2}{*}{\multicolumn{7}{|c|}{ Suspension Geometry Requirements }} \\
\hline Anti-Roll Bars & & & & & & \\
\hline \multicolumn{7}{|l|}{ Relationship to ride } \\
\hline \multicolumn{7}{|l|}{ Glossary } \\
\hline & & & & & & \\
\hline Bibliography & & & & & & \\
\hline
\end{tabular}

Figure 1 (Contd. ) 
Team Experience Check List and Evaluation Sheet email:rlundstr@beretta.gmi.edu

\title{
BOLL MANAGEMENT EXPERIENCE REPORT CONTENT. CHECK LIST AND EVALUATION SHEEI
}

\author{
DU⿴囗口回居:
}
UNDERSTANDING SUSPENSION ROLL CHARACTERISTICS AND HOW THEY ARE RELATED TO PROVIDING QUALITY RIDE AND HANDLING PERFORMANCE

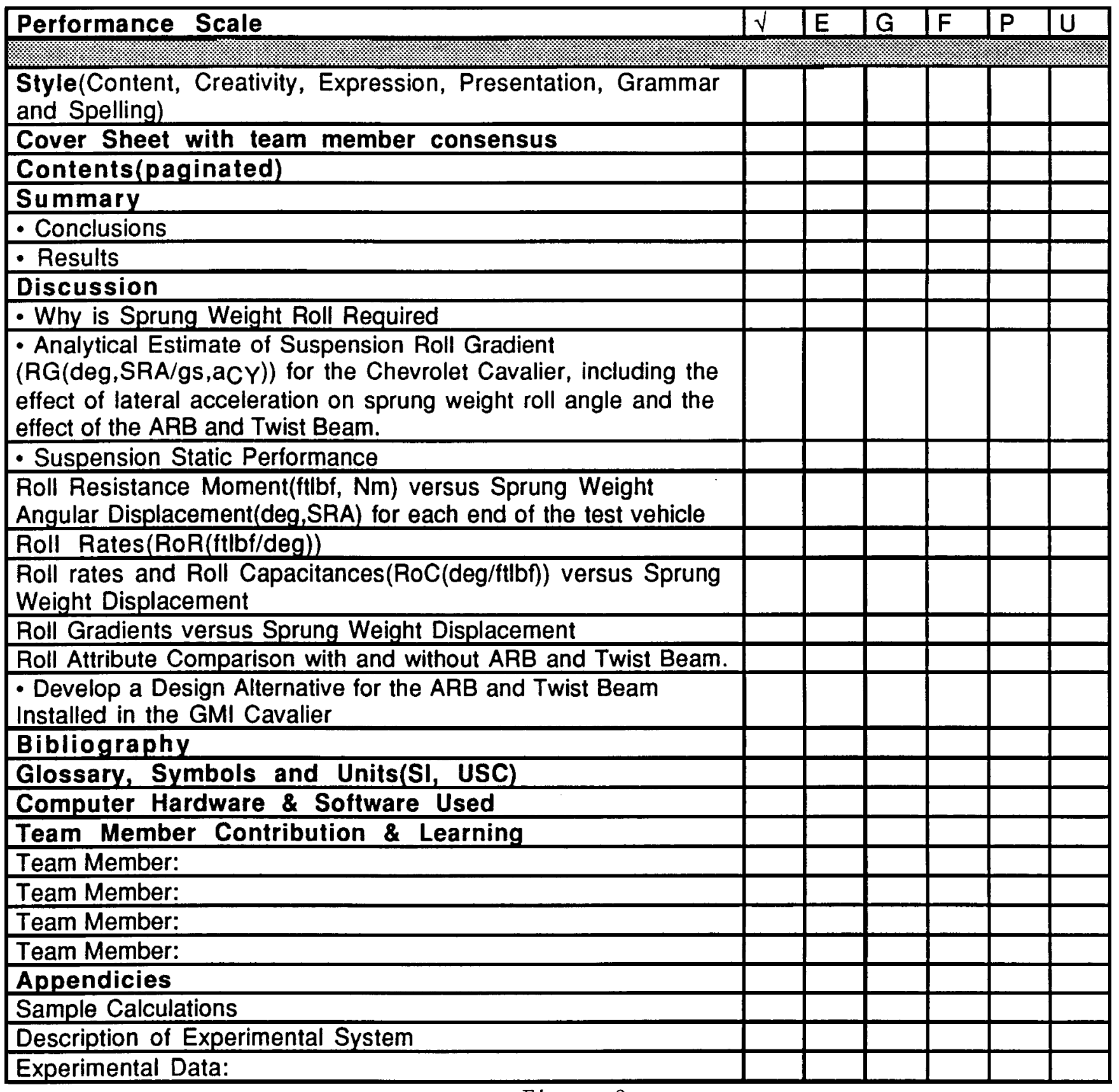

Figure 2 
Course Handbook Contents(16-Ott-95)

ME-421

Chassis Design
Hours: 0900 to 0950, MTW

also by appointment

TEL

FAX

email: rlundstr@beretta.gmi.edu

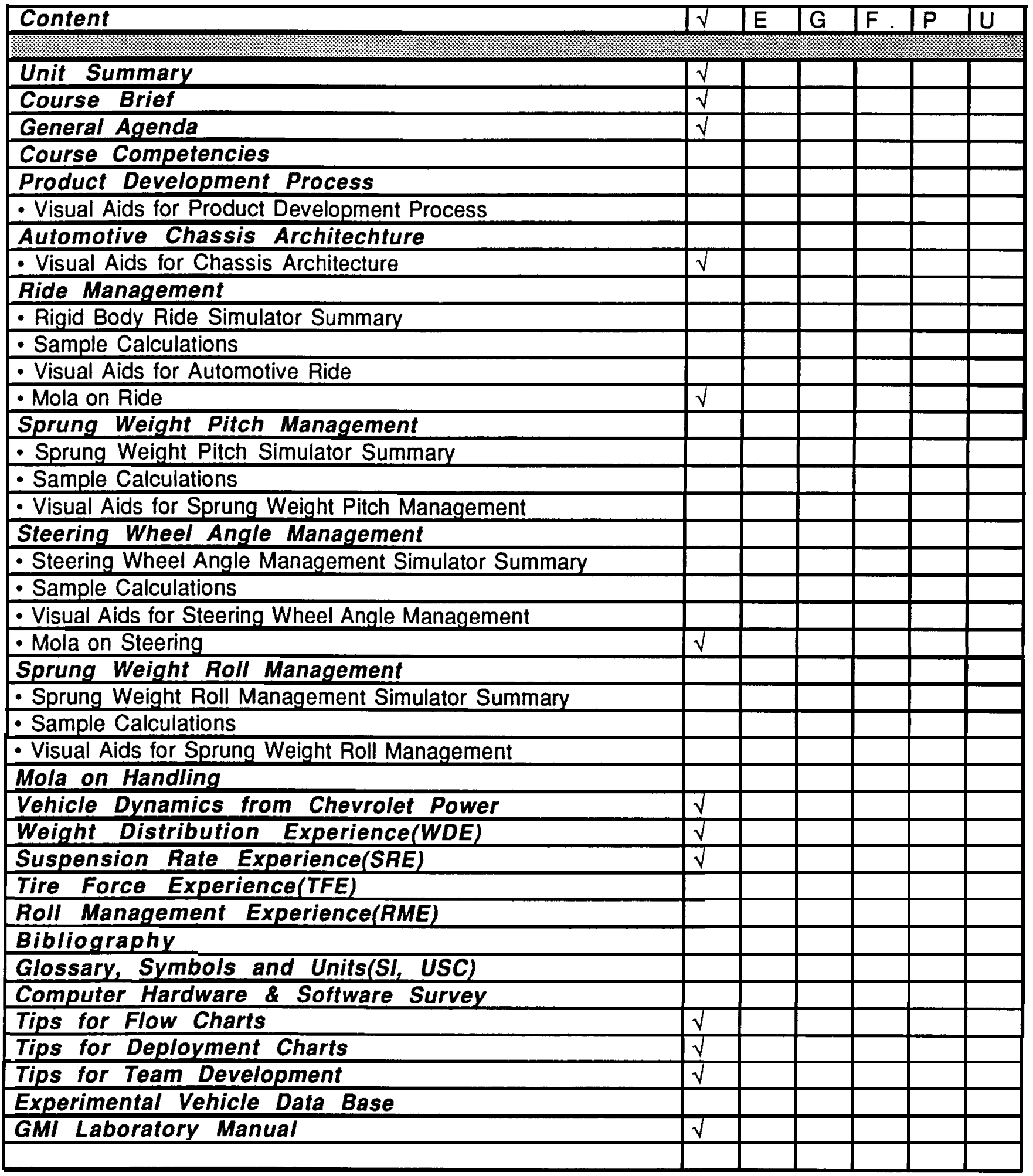




\section{References}

1. ASEE Prism, 1995 , pp. 10, November

2. Bieniawski, z. T., 1995, Curriculum Design By Engineering Design Principles, ASEE Conference Proc., pp. 1780-1784.

3. Cage, M. C., 1995, Re-Engineering, The Chronicle of Higher Education, Vol. XLI, April. •

4. Cornesky, R. A., 1994, Quality Classroom Practices for Professors, Cornesky Associates, Port Orange.

5. Clausing, D., 1994, Total Quality Development, ASME Press, NY.

6. Cornesky, R. A., 1993, The Quality Professor, Magna Publications, Madison.

7. Covey, S., 1989, The Seven Habits of Highly Effective People, Fireside, New York.

8. Covey, S., 1990, Principle-Centered Leadership, Fireside, New York.

9. Deming, Edwards, 1993, The New Economics, Massachusetts Institute of Technology.

10. Dixon, J. R, 1991, New Goals for Engineering Education, Mechanical Engineering, March, pp. 56-62.

11. Furman, B. J., Towards a More Hands-on, Design -Oriented Course on Mechanisms, 1995, ASEE Annual Conference Proc., pp. 2763-2770.

12. Glasser, William, Control Theory of Human Behavior,

13. Glasser, William, 1993, The Quality School Teacher, HarperCollins, NY.

14. Hauser, J. R., and Clausing, D., 1988, The House of Quality, Harvard Business Review, pp. 63-73

15. Howell, S. K, et al., An Integrated Engineering Design Experience: Freshmen to Senior Level, 1995 , ASEE Annual Conference Proc., pp. 2598-2606.

16. Langford, D., 1994, Four Days of Quality Learning, Langford International, Inc., Billings, Montana.

17. Roberts, H. and Sergesketter, B., 1993, Quality is Personal, The Free Press, New York.

18. Shigeo Shingo, 1989, A Study of the Toyota Production System, Productivity Press.

19. Taiichi Ohno, 1988, Toyota Production System, Productivity Press.

20. Wilczynski, V., and Douglas, S. M., 1995, Integrating Design Across the Engineering Curriculum: A Report From the Trenches, J. of Engineering Education, pp. 235-240.

\section{RICHARD LUNDSTROM}

Richard Lundstrom is a Professor of Mechanical Engineering at GMI Engineering \& Management Institute. He received his B.S. from the University of Illinois, M.S. from the University of Michigan and Ph.D. from Oakland University.

\section{JAWAHARLAL MARIAPPAN}

Jawaharlal Mariappan is an Assistant Professor of Mechanical Engineering at GMI Engineering \& Management Institute. He received his integrated M.S. degree in Mechanical Engineering from Peoples Friendship University, Moscow, and Ph.D. from the University of Massachusetts, Amherst.

\section{JOEL BERRY}

Joel Berry a Professor and Head of Mechanical Engineering at GMI Engineering \& Management Institute. He received his B.S. in Mechanical Engineering from General Motors Institute, M.S. from Michigan State University and Ph.D. from the Carnegie Mellon University. 